\title{
Establishment of suspension cultures of Salvadora persica L. for benzyl isothiocyanate production
}

\author{
Ghada Abd El-Moneim Hegazi \\ Tissue Culture Unit, Department of Genetic Resources, Ecology and Dry Land Agriculture Division, Desert \\ Research Center, 11753 El-Matareya, 1 Mathaf El-Matareya St., Cairo, Egypt
}

\begin{abstract}
Successful scale-upof the anticancer benzyl isothiocyanate compound production was achieved from cell suspension cultures of Salvadora persica L. Cell cultures were established from the stem internodal segments derived callus. Elicitation with two biotic elicitors; chitosan and salicylic acid, increased callus biomass and benzyl isothiocyanate accumulation, but chitosan induced the maximum accumulation, which reached about four-fold higher over the control at the concentration of $100 \mathrm{mg} / \mathrm{L}$. Benzyl isothiocyanate production from cell suspension cultures was studied in shake-flask culture and stirred-tank bioreactor with the application of the optimum concentration of chitosan in the medium. Both methods elevate the compound production; however its yield was higherin the stirred-tank bioreactor.It achieved about eight-fold increase in the production of benzyl isothiocyanate after 24 days of incubation. This protocol can act as a roadmap for large-scale production of benzyl isothiocyanate from cell suspension cultures ofSalvadora persica by using bioreactors.
\end{abstract}

Keywords:plant cell culture, chitosan, salicylic acid, shake-flask culture, stirred-tank bioreactor

\section{Introduction}

Plants are the primary and natural source of a huge number of secondary metabolites, which are used as pharmaceuticals, food additives, flavors, fragrances, colors, agrochemicals and biopesticides. The production of secondary metabolites in the plants is very low (less than $1 \%$ dry weight) and depends greatly on the physiological and developmental stage of the plant ${ }^{[1]}$.Plant cell and tissue cultures represent sustainable, ecofriendly and cost-effective alternative to the extraction of the whole plant material for production of valuable phytochemical compounds. Among other advantages, plant cell and tissue cultures lead to have a higher rate of metabolism when compared to field grown plants ${ }^{[2,3]}$. Furthermore, in vitrocultures offer uniform secondary product synthesis under controlled conditions by overcoming the effect of climatic conditions and diseases in field grown or natural plants ${ }^{[4]}$.

Various strategies have been developed to improve the in vitro production of secondary metabolites ${ }^{[5]}$. For the large-scale production of valuable compounds, first of all, the establishment of callus biomass from selected highly productive plant genotypes is required. The callus has an unlimited growth capacity and can synthesize the same compounds as the original plant. Cell suspension cultures derived from the callus are first maintained on a small scale and then at bioreactor level ${ }^{[6]}$. Scale-up of plant cells in the bioreactor is the key step towards commercial production of secondary metabolites. Stirred-tank bioreactors (mechanically agitated) have been the most versatile bioreactor system for large-scale production of plant cells. They are highly effective for proper mixing of cell suspensions and the break-up of air bubbles to enhance oxygenation and prevent large cell aggregates formation ${ }^{[7]}$.

Elicitation is one the most effective strategies for improving the in vitro production of secondary metabolites ${ }^{[8]}$.Elicitors can stimulate plant defense, leading to the enhanced synthesis and accumulation of secondary metabolites ${ }^{[2]}$. According to their origin, elicitors are divided into abiotic and biotic elicitors. Abiotic elicitors are substances of non-biological origin, being inorganic compounds; such as salts or physical factors ${ }^{[9]}$.Biotic elicitors include substances of pathogenic origin (exogenous elicitors) and compounds produced by plants after the action of the pathogen (endogenous elicitors) ${ }^{[3,10]}$.Chitosan and salicylic acid are biotic elicitors. Chitosan is considered as an exogenous elicitor. It is a polysaccharide and the deacetylated form of chitin, which is the main component of the cell wall of some fungi and simulate the effects of pathogenic microorganisms on plants to biosynthesize secondary metabolites ${ }^{[11]}$.On the other hand, salicylic acid is an endogenous elicitor. It is a small molecule and considered as a plant hormone with a vital role in plant defense regulatory systems to many pathogen ${ }^{[12]}$. It stimulates a wide range of defense responses, including the production of plant secondary metabolites ${ }^{[13]}$.

Salvadora persica L. (family Salvadoraceae) is an economically and medicinally important plant belonging to the flora of Egypt ${ }^{[14]}$. It is an evergreen tree or shrub commonly known as Miswak. Miswak is a natural toothbrush, which has been documented to have a potent antibacterial effect ${ }^{[15]}$. The different parts of the plant contains many active constituents that possess a broad spectrum of biological and pharmacological effects, 
such as anti-microbial, anti-viral, anti-diabetic, anti-fungal, anti-cancer, anti-ulcer, anti-plaque, anti-caries, antiplasmodial, oral hygienic activities, antidepressant, wound-healing, anti-gingival irritation, hypoglycemia, antioxidant, anti-fever, anti-ulcerogenic, anti-caries and antiplatelet-agression effect, corrective, deobstruent, liver tonic, diuretic, analgesic, anthelmintic, astringent, lithontriptic, carminative, diuretic, aphrodisiac, and stomachic $^{[16,17,18]}$

Benzylisothiocyanate (BITC) is the major active constituent of S.persica. It is one of the isothiocyanates with the strongest anticancer properties in human cancer cells. BITC reduce risk of cancers of the lung, esophageal, breast ${ }^{[19,20]}$, gastrointestinal, pancreatic and colon ${ }^{[21]}$ by blocking cancer development. Also, it inhibits growth and triggers apoptosis of human oral cancer cells with a minimal toxicity to normal cells ${ }^{[22]}$.BITC efficiently inhibits several cancer promoting-cytochrome enzymes, helping to prevent carcinogenesis $^{[23]}$. Moreover, it is the main antibacterial component in S. persica and exhibits rapid and strong bactericidal effect against oral pathogens involved in periodontal disease ${ }^{[24]}$. A previous study was carried out by Hegazi et al. ${ }^{[25]}$ on the in vitro production of BITC from $S$. persica callus cultures generated from leaf and stem internodal explants; determining the effect of different plant growth regulators and two amino acid precursors; phenylalanine and cysteine, on the callus growth and BITC accumulation. It proved that the callusing response from stem internodal explants was much higher than that of the leaf, andphenylalanineincreased the accumulation of BITC in callus cultures.

The present research work is aimed to scale-up BITC production from $S$. persica cells in shake-flask culture and stirred-tank bioreactor under similar nutrient and environmental conditions, after the investigation of the effect of chitosan and salicylic acid as biotic elicitors on BITC accumulation.

\section{Induction ofcallus culture}

\section{Materials and Methods}

Stem internodal segmentsfrom young S.persicaplantsgrown in the Egyptain Botanical Garden (Orman) were used as explants. Explants were taken from plants originated from seeds collected from naturally grown plants in Gabal Elba, south Egypt. The stem intermodal segments $(2-3 \mathrm{~cm}$ long) were initially washed thoroughlyunder running tap water for 10 minutes and surface sterilized under complete aseptic conditions with $30 \%(\mathrm{v} / \mathrm{v})$ commercial bleach [containing 5.25\% sodium hypochlorite $(\mathrm{NaOCl})$ ] for 10 minutes, followed by dipping in $0.1 \%(\mathrm{w} / \mathrm{v})$ mercuric chloride $\left(\mathrm{HgCl}_{2}\right)$ for 45 seconds. Finally, explants were thoroughly rinsed five times with sterilized distilled water. The cutting ends of the stem internodal segments were trimmed for culturing.

Callus culture was developed from explantsand maintained on ready-made solid Murashige and Skoog (MS) basal medium ${ }^{[26]}$ (Caisson, USA) supplemented with $100 \mathrm{mg} / \mathrm{L}$ myo-inositol, $3 \% \mathrm{w} / \mathrm{v}$ sucrose and 0.5 $\mathrm{mg} / \mathrm{L}$ of each of 2,4-dichlorophenoxy acetic acid (2,4-D) and Kinetin (Kin)(the optimal medium composition of callus inductionas reported by Hegazi et al. ${ }^{[25]}$ ). Chemicals added to the culture medium were supplied by Sigma Chemical Co., USA. The $\mathrm{pH}$ of the medium was adjusted to 5.7-5.8 and solidified with 0.7\% w/v agar. Media (40-45 ml volumes) were dispensed into glass jars. Jars were sealed with autoclavable polypropylene caps and autoclaved at $1.1 \mathrm{~kg} / \mathrm{cm}^{2}$ for 15 minutes at $121^{\circ} \mathrm{C}$.

Cultures were maintained under a 16-hourphotoperiod provided by cool-white fluorescent tubes (F $140 \mathrm{t} 9 \mathrm{~d} / 38$, Toshiba) at a temperature of $25 \pm 2^{\circ} \mathrm{C}$ and $70 \pm 10$ relative humidity. Callus cultures thus raised were subcultured to fresh medium after four weeks.

\section{Elicitation}

An amount of $5 \mathrm{~g}$ of callus fresh weight/jar was transferred to the same medium composition in addition to different concentrations of chitosan $(100,200$ and $300 \mathrm{mg} / \mathrm{L})$ and salicylic acid $(5,10$ and $20 \mathrm{mg} / \mathrm{L})$ as biotic elicitors, in addition to the control treatment without elicitors. Callus was collected and the fresh and dry weights were determined. Dry weight was determined after drying the callus at $45^{\circ} \mathrm{C}$ in an oven until a constant weight was obtained. Also, BITC concentration was recorded for each treatment. Data were documented after four weeks of culture.

\section{Establishment of suspension cultures}

\subsection{Shake-flask culture experiment}

Suspension cultures were established from $3 \mathrm{~g}$ fresh friable callus in $100 \mathrm{ml}$ Erlenmeyer flasks containing $30 \mathrm{ml}$ of theliquid optimized MS medium that containing0.5 mg/L of each of 2,4-D and Kin, in addition to $100 \mathrm{mg} / \mathrm{L}$ chitosan. The $\mathrm{pH}$ of the medium was adjusted to 5.7-5.8 before autoclaving as mentioned previously. Flasks were closed with cotton plugs and two layers of aluminum foil and incubated on a rotary shaker (DAIHAN Scientific, Korea) with speed of $100 \mathrm{rpm}$ at $25 \pm 2{ }^{\circ}$ Cundera 16 -hour photoperiod in the growth room. Cultured cells were sampled at each growth stage up to the $28^{\text {th }}$ day of incubation in 7 -day intervals and BITC concentration was determined. 


\subsection{Bioreactor experiment}

A stirred-tank bioreactor (STB) system (Applicon, Dependable Instruments, The Netherlands) was used in the present study; consisted of $3 \mathrm{~L}$ autoclavable cylindrical glass vessel. An amount of $20 \mathrm{~g}$ of S.persicacellswere cultivated into the culture vessel containing $2 \mathrm{~L}$ (working volume) ofthe optimized medium (MS medium supplemented with $0.5 \mathrm{mg} / \mathrm{L}$ of each of 2,4-D and Kin, in addition to $100 \mathrm{mg} / \mathrm{L}$ chitosan).The rotation speed was kept constant at $100 \mathrm{rpm}$ throughout the cultivation. The cultures were aerated through a sintered stainless-steel sparger. The air flow rate was adjusted manually to the required level using an air flow control system. The temperature and $\mathrm{pH}$ in the bioreactor were controlled at $27^{\circ} \mathrm{C}$ and $5.7-5.8$, respectively, by bio-controller (ADI 1032, Applicon, Dependable Instruments, The Netherlands). Dissolved oxygen (DO) and $\mathrm{pH}$ were monitored with autoclavable electrodes. Impeller vertically orientated for liquid flows away from the motor axis was used for agitation.Samples were collected in 7-day intervals up to the $28^{\text {th }}$ day for the quantitative analysis of BITC.

\section{Analysis of benzyl isothiocyanate content}

The determination of BITC was performed by high performance liquid chromatograph (HPLC) as described by Kiddle et al. ${ }^{[27]}$ and modified by Rossetto et al. ${ }^{[28]}$. The extraction of BITC was carried out from callus and cells from shake-flask culture and stirred-tank bioreactor experiments according to Kiddle et al. ${ }^{[27]}$ with minor modifications. Samples were homogenized in a porcelain mortar containing 70: 30 (v:v) $\mathrm{MeOH}$ :water. Extracts were transferred to stoppered Erlenmeyer flasks and conditioned in a thermostatic bath under constant agitation. The extraction was carried out at $70^{\circ} \mathrm{C}$ for 30 minutes. The extracts were filtered on Millex ${ }^{\mathrm{TM}}$ polyvinylidene fluoride (PVDF) membranes ( $0.45 \mu \mathrm{m}$, Millipore) prior to HPLC injection. Methanolic extracts of samples were analyzed by HPLC for BITCconcentration using an external standard. HPLC system (Agilent 1100 series, Waldborn, Germany) was coupledwith UV-Vis detector (G1315B) and G1322A Degasser. Sample injectionsof $10 \mu \mathrm{l}$ were made by an Agilent 1100 Series auto-sampler; thechromatographic separations were performed on ZORBAX-EclipseXDB-C18 column $(4.6 \times 250 \mathrm{~mm}$, particle size $5 \mu \mathrm{m})$. Column temperature was maintained at $30^{\circ} \mathrm{C}$ and detection wavelength was $254 \mathrm{~nm}$. Optimum efficiencyofseparation was obtained using methanol (solvent A), and theacitonitrile (solvent B) (HPLC grade). The flow rate was $1 \mathrm{ml} / \mathrm{minute}$. The run time for each analysis was 60 minutes, and 10 minuteswere required for column cleaning and equilibrium. The BITC concentration of the injected samples was calculated as $\mu \mathrm{g} / \mathrm{g}$ fresh weight of sample.

\section{Data analysis}

Experiments were conducted in a completely randomized designwith at least 20 replicates per treatment for the callus culture experiment and three replicates for the cell suspension culture experiments. Data were subjected to statistical analyses by Anova programme using Duncan's multiple range tes ${ }^{[29]}$ as modified by Snedecor and Cochran ${ }^{[30]}$.Values marked with different letters were considered to be statistically different at $p_{-}<-$ 0.05 .

\section{Elicitation}

\section{Results and Discussion}

S. persica callus cultures derived from stem internodal segments accumulated BITC as a response to chitosan and salicylic acid, which acted as biotic elicitors (Table 1). The two elicitors were screened for various concentrations for high quantity of BITC accumulation. Both elicitors showed significant increase in BITC accumulation over the control cultures with insignificant increase in the fresh weight of callus. Callus treated with chitosan increased BITC accumulation compared with that of salicylic acid. Maximum accumulation of BITC $(4.534 \mu \mathrm{g} / \mathrm{g}$ fresh weight) was recorded after the treatment with chitosan at the concentration of 100 $\mathrm{mg} / \mathrm{L}$, which achieved about 3.7-fold increase in the BITC production over the control treatment $(1.239 \mu \mathrm{g} / \mathrm{g}$ fresh weight), and also achieved the highest fresh and dry weight of callus (Fig. 1). Despite this treatment was the optimum, BITC production decreased above this concentration level of chitosan $(200$ and $400 \mathrm{mg} / \mathrm{L})$ in the medium. The callus treated with different concentrations of salicylic acid $(5-20 \mathrm{mg} / \mathrm{L})$ showed maximum BITC accumulation (1.690 $\mu \mathrm{g} / \mathrm{g}$ fresh weight) at $5 \mathrm{mg} / \mathrm{L}$, which slightly raised the yield of BITC over the control. It recorded an increase of 1.4 times over the control treatment. The increase in salicylic acid elicitor concentration led to a decline in the BITC accumulation. The best dose of the elicitors with maximum accumulation of BITC was used in further experiments ( $100 \mathrm{mg} / \mathrm{Lchitosan})$. 
Table 1.Effect of different concentrations of chitosan and salicylic acid on the callus weight and accumulation of BITC in callus cultures of Salvadora persicaon MS medium supplemented with $0.5 \mathrm{mg} / \mathrm{L}$ of both of 2,4-D and Kin.

\begin{tabular}{|l|l|l|l|}
\hline $\begin{array}{l}\text { Elicitor concentration } \\
(\mathbf{m g} / \mathbf{L})\end{array}$ & Fresh weight $(\mathbf{g})$ & Dry weight $(\mathbf{g})$ & $\begin{array}{l}\text { Conc. of BITC }(\boldsymbol{\mu g} / \mathbf{g} \text { fresh } \\
\text { weight })\end{array}$ \\
\hline Control & & & \\
\hline $\mathbf{0}$ & $5.044^{\mathrm{a}}$ & 1.239 \\
\hline Chitosan & & $4.521^{\mathrm{d}}$ & \\
\hline $\mathbf{1 0 0}$ & $6.104^{\mathrm{a}}$ & & 4.534 \\
\hline $\mathbf{2 0 0}$ & $5.518^{\mathrm{a}}$ & $5.700^{\mathrm{a}}$ & 2.443 \\
\hline $\mathbf{4 0 0}$ & $4.914^{\mathrm{a}}$ & $5.000^{\mathrm{b}}$ & 2.045 \\
\hline Salicylic acid & $4.567^{\mathrm{d}}$ & \\
\hline $\mathbf{5}$ & & & 1.690 \\
\hline $\mathbf{1 0}$ & $5.678^{\mathrm{a}}$ & $4.903^{\mathrm{c}}$ & 1.624 \\
\hline $\mathbf{2 0}$ & $4.900^{\mathrm{a}}$ & $4.400^{\mathrm{e}}$ & 1.531 \\
\hline
\end{tabular}

In each column, mean followed by the same subscripted letter was not significantly different $(p<0.05)$ according to the Duncan's multiple range test

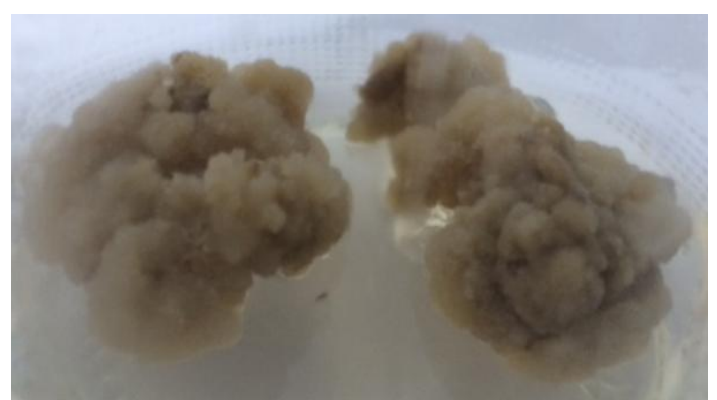

Fig. 1.Callus of Salvadora persica on MS medium supplemented with $0.5 \mathrm{mg} / \mathrm{L}$ of both of 2,4-D and Kin in addition to $100 \mathrm{mg} / \mathrm{L}$ chitosan.

It is observed that BITC production is highly affected by the addition of biotic elicitors. Therefore, elicitation offers an attractive strategy for increasing the secondary metabolite in vitro production ${ }^{[31]}$. This study showed that both chitosan and salicylic acid increased accumulation of BITC in callus culture of $S$. persicaover the control. Chitosan and salicylic acid have been reported to enhance the in vitro production of secondary metabolites in various plants ${ }^{[32]}$, such a stimulatory effect may be due to the stimulation of biosynthetic enzymes $^{[33]}$. Chitosan is the main structural component of the cell wall of plant pathogen fungi, which mimics its effects and activates the biosynthesis of defense-related secondary metabolites in plants ${ }^{[8,11,34]}$.Also, salicylic acid has an important role in the defense against attacks by microbes and herbivores, and against abiotic stresses, hence, it is very often used in plant in vitro cultures as an elicitor ${ }^{[32,35]}$. It was observed that chitosan was better for the enhancement of the production of BITC than salicylic acid. The same observation was reported by Palee et al. ${ }^{[3]}$, who revealed that chitosan was better than salicylic acid for the enhancement of the in vitro production of three stemona alkaloids from Stemona curtisii. Chitosan has been used as a strong elicitor to improve the in vitro production of secondary metabolites of other numerous plants, for example, Ocimum basilicum $^{[36]}$ and Withania somnifera ${ }^{[37]}$.Another significant effect of the elicitors observed in this experiment was that the accumulation of BITC is elicitor dose dependent. The increase in BITC accumulation with elicitor application was observed and the increase in elicitor concentration over the optimum concentration led to decrease in the BITC content in callus cultures. Similar results were reported in taxol ${ }^{[38]}$, ajmalicine ${ }^{[39]}$ and psoralen $^{[4]}$ production.

\section{Cell suspension cultures}

Cell suspension cultures offer an alternative way to traditional agriculture for industrial production of various valuable phytochemicals. The liquid culture has many advantages compared to solid one. The contacting surface area of cells and media is much larger, which permit cells to utilize the well mixed nutrients much easier. Also, harmful compounds that may be formed can be effectively diluted, which prevents the inhibition of cell growth ${ }^{[40]}$. Fig. 2 shows the effect of elicitation with the optimum concentration of chitosan $(100 \mathrm{mg} / \mathrm{L}) \mathrm{on}$ 
BITC accumulation in shake-flask culture and stirred-tank bioreactor during different durations of incubation time. Successful scale-up of BITC accumulationwas achieved from cell suspension cultures using both methods. Its accumulation varied from 7 to 28 days of incubation and increased with increasing in the duration of incubation time. This result indicates that the duration of cell cultured with the elicitor is important for the maximum BITC accumulation. This agrees with Karwasara et al. ${ }^{[41]}$ and Ahmed and Baig ${ }^{[4]}$, who stated that the amount of metabolite production varied with duration time of incubation with elicitors. The optimum incubation time for BITC accumulation with chitosan was found to be 21 days for both shake-flask culture and bioreactor.

Comparing BITC accumulation in S. persica cell cultures between shake-flask and stirred-tank bioreactor systems is shown in Fig. 2. In general, BITC yield was higher in the bioreactor than that using shakeflask culture during all the studied durations. Using the bioreactor, BITC content was 10.078 and $11.98 \mu \mathrm{g} / \mathrm{g}$ fresh weight after 7 and 14 days of incubation, respectively. BITC content increased significantly after 21 days, reaching the maximum value of $36.189 \mu \mathrm{g} / \mathrm{g}$ fresh weight, which achieved about 8 -fold increase, then it declined (reaching $24.459 \mu \mathrm{g} / \mathrm{g}$ fresh weight of only 5.4 -fold increase). The BITC content was higher in the bioreactor by about 1.5, 1.1, 2.3 and 2 times than the shake-flask culture after 7, 14, 21 and 28 days, respectively. Only after 14 days they were more or less the same. Both gave the maximum BITC accumulation after 21 days and declined after 28 days. The decreased BITC accumulation could be due to arrest of cell growth, degradation or conversion of BITC to some other chemical forms or due to change in medium nutrient composition.

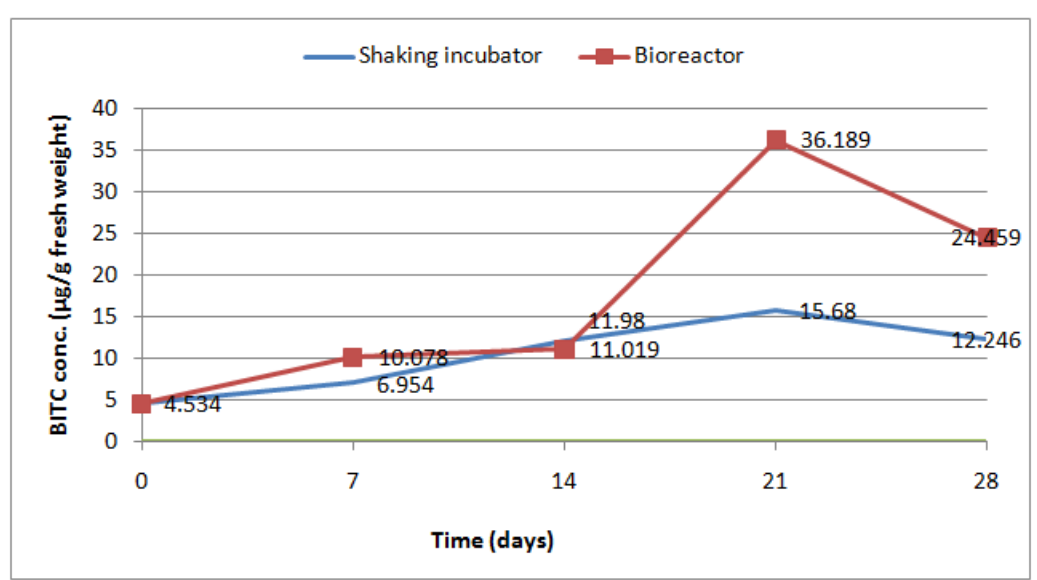

Fig.2.BITC yield of Salvadora persica cell suspension cultures after different durations of incubation time in shake-flask culture and stirred-tank bioreactor in MS medium supplemented with $0.5 \mathrm{mg} / \mathrm{L}$ of both of 2,4-D and Kin in addition to $100 \mathrm{mg} / \mathrm{L}$ chitosan.

The different performance between shake-flask culture and the stirred-tank bioreactor could be due to the difference in hydrodynamic conditions and gas compositions between the two systems. The large surface area for the air medium interface in the shake-flask and the bioreactor systems (larger container) provide an adequate amount of oxygen and nutrient mass transfer ${ }^{[40]}$. It was reported earlier that the plant cell growth environment in a bioreactor is different from that in Erlenmeyer flasks; changes in shear stress, oxygen supply and gas composition are expected.Cell suspension cultures grown in bioreactors are exposed to higher hydrodynamic stress in comparison to those in Erlenmeyer flasks that causes damage of the plant cell cultures; include alteration in single cells and aggregate size and shape, lower cell growth and viability, and/or decrease in secondary metabolite production ${ }^{[42]}$. However, there are some examples confirming the results of the present study and demonstrating that exposure to shear stress as a result of cultivation in a bioreactor enhances secondary metabolite production. Chen and Huang ${ }^{[43]}$ reported that a high shear stress favored the production of L-DOPA by cells of Stizolobium hasjoo in a stirred-tank bioreactor. They proposed that shear stress generated a proton elicitation, and this might be responsible for the enhancement of L-DOPA production. In addition, Trejo-Tapia et al. ${ }^{[42]}$ found that in the stirred-tank bioreactor, Uncaria tomentosa cells afforded higher levels of MOA than in Erlenmeyer flasks. Also, a successful scale-up of Azadirachta indica suspension culture for azadirachtin production was done in stirred tank bioreactor ${ }^{[7]}$.

In general, application of the bioreactor is one of the prerequisites for industrialization of plant cell culture. They can provide well mixed media and sterile air. There are many successful researches on cell and tissue culture of medicinal herbs to produce useful secondary metabolites through bioreactors, which demonstrated the industrial potential of using bioreactor in producing valuable phytochemicals ${ }^{[40]}$. 


\section{Conclusion}

This is the first report on the production of BITC from cell suspension cultures of S. persica in a shakeflask and bioreactor systems. The results of this study show that the application of the biotic elicitor; chitosan,enhanced BITC synthesis inS. persica callus culturewhen compared to the untreated callus or that treated with salicylic acid.Moreover, the present investigation established the feasibility of large-scale BITC production in stirred-tank bioreactors, where S. persica cells afforded higher levels of BITC production (reached about 8-fold after 21 days of incubation) than in Erlenmeyer flasks.The results obtained from the present study can act as a roadmap for further studies regarding large-scale production of BITC from S. persica cell suspension cultures by using bioreactors.

\section{References}

[1]. K.M.Oksman-Caldentey, and D.Inze, Plant cell factories in the post-genomic era: new ways to produce designer secondary metabolites. Trends Plant Sci,9,2004, 9.

[2]. P.M.Naik, andJ.M.Al-Khayri,Abiotic and biotic elicitors-role in secondary metabolites production through in vitro culture of medicinal plants (http://dx.doi.org/10.5772/61442,Intech, 2016).

[3]. K.Ramirez-Estrada, H.Vidal-Limon, D.Hidalgo, E.Moyano, M.Golenioswki, R.M.Cusidó, andJ.Palazon, Elicitation, an effective strategy for the biotechnological production of bioactive high-added value compounds in plant cell factories. Molecules,21,2016, 182.

[4]. S.A.Ahmed, and M.M.V.Baig,Biotic elicitor enhanced production of psoralen in suspension cultures of Psoralea corylifolia L. Saudi JBiolSci, 21, 2014,499-504.

[5]. H.A.Azeez, and K.M. Ibrahim, Effect of biotic elicitors on secondary metabolite production in cell suspensions of Hypericum triquetrifolium Turra. BullUASVM Hort, 70(1),2013,26-33.

[6]. R.M.Cusido,M.Onrubia,A.B.Sabater-Jara,E.Moyano,M.Bonfill, andA.Goossens et al., A rational approach to improving the biotechnological production oftaxanes in plant cell cultures of Taxus spp. Biotechnol Adv,32,2014, 1157-1167.

[7]. G.Prakash, and A.K.Srivastava, Azadirachtin production in stirred tank reactors by Azadirachta indica suspension culture. Process Biochem,42, 2007, 93-97.

[8]. E.Wiktorowska, M.Długosz, and W.Janiszowska, Significant enhancement of oleanolic acid accumulation by biotic elicitors in cell suspension cultures of Calendula officinalis L. Enzyme Microbial Technol,46,2010,14-20.

[9]. J.Gorelick, and N.Bernstein, Elicitation: an underutilized tool in the development of medicinal plants as asource of therapeutic secondary metabolites,in D.L. Sparks (Ed.), Advances in agronomy, 124. (Elsevier: Amsterdam, The Netherlands, 2014) $201-230$.

[10]. S.A.Zebelo,and M.E. Maffei,Role of early signalling events in plant-insect interactions. J Exp Bot, 66,2015, $435-448$.

[11]. C.H.Zhang, P.S.Fevereiro, G.He, and Z.Chen, Enhanced paclitaxel productivity and release capacity of Taxus chinensis cell suspension cultures adapted to chitosan. Plant Sci, 172(1),2007,158-163.

[12]. Q.Hayat,S.Hayat,M.Irfan, andA.Ahmad, Effect of exogenous salicylic acid under changing environment: A review. Environ Exp Bot, 68,2010,14-25.

[13]. Z.Dǔcaiová,V.Petrul’ová,and M.Rep`cák, Salicylic acid regulates secondary metabolites content in leaves of Matricaria chamomilla. Biologia (Bratisl),68,2013, 904-909.

[14]. L.Boulos,Flora of Egypt cheklist. (Revised Annonated Edition, Alhadara Publishing, Egypt, 2009).

[15]. K.I.Al-Zubaidy,In vitro comparison of the antibacterial effect between miswak and some toothpastes on oral biofilm forming bacteria. World J Pharm Res,5(6),2016,1-13

[16]. J.Akhtar, M.S.Khalid, B.Salma, and M.Mujeeb,A review on phytochemical and pharmacological investigations of miswak (Salvadora persica Linn). J PharmBioallied Sci,3(1),2011, 113-117.

[17]. M.Arora, and V.K.Gupta, Phytochemical and biological studies on Salvadora persica Wall: A review. Pharmacologyonline, 1,2011,591-601.

[18]. H.Ahmad, andK. Rajagopal, Biological activities of Salvadora persica L. (Meswak). Medicinal and Aromatic Plants,2(4),2013,129.

[19]. A.Sehrawat, and S.V.Singh, Benzyl isothiocyanate inhibits epithelial-mesenchymal transition in cultured and xenografted human breast cancer cells. Cancer Prevention Research (Philadelphia, Pa.),4(7),2011,1107-1117.

[20]. B.Xie, A.Nagalingam, P.Kuppusamy, N.Muniraj, P.Langford, andB.Győrffyet al.,Benzyl isothiocyanate potentiates p53 signaling and antitumor effects against breast cancer through activation of p53-LKB1 and p73-LKB1 axes. Scientific Reports, 7,2017, Article number: 40070 .

[21]. K.S.Srivastava, and R.P.Sahu,Response: Re: The Role of STAT-3 in the induction of apoptosis in pancreatic cancer cells by benzyl isothiocyanate. J Natl Cancer Inst,101(12),2009,893-894.

[22]. T.-T.Yeh, Y.-N.Hsu, S.-Y.Huang, J.-S.Lin, Z.-F.Chen, and N.-H.Chowet al., Benzyl isothiocyanate promotes apoptosis of oral cancer cells via an acute redox stress-mediated DNA damage response. Food Chem Toxicol,97,2016, 336-345.

[23]. L.B.Von Weymarn, J.A.Chun,and P.F.Hollenberg, Effects of benzyl and phenethylisothiocyanate on P450s 2A6 and 2A13: potential for chemoprevention in smokers. Carcinogenesis,27(4),2006,782-790.

[24]. A.Sofrata, M.S.Ellen, M.Azeem, A.K.Borg-Karlson, A.Gustafsson, and K.Pütsep, Benzyl isothiocyanate, a major component from the roots of Salvadora persica is highly active against gram-negative bacteria. PLoS One,6(8),2011,e23045.

[25]. Gh.A.Hegazi, N.A.El-Hanafy, Z.A.Abu-Elkheir,and I.A.Hussein, Benzyl isothiocyanate production from Salvadora persica L. callus cultures. IOSR J Biotechnol Biochem,2(2),2016, 19-25.

[26]. T.Murashige, and F.Skoog, A revised medium for rapid growth and bioassays with tobacco tissue cultures. Physiol Plant,15,1962, 473-497. 
[27]. G.Kiddle, R.N.Bennett, N.P.Botting, N.E.Davidson, A.A.B.Robertson, and R.M.Wallsgrove, High-performance liquid chromatographic separation of natural and synthetic desulphoglucosinolates and their chemical validation by UV, NMR and chemical ionisation-MS methods. Phytochemical Analysis, 12(4),2001, 226-242.

[28]. M.R.M.Rossetto, J.R.O.Nascimento, E.Purgatto, J.P.Fabri, F.M.Lajolo, and B.R.Cordenunsi, Benzylglucosinolate, benzylisothiocyanate, and myrosinase activity in papaya fruit during development and ripening. JAgric Food Chem,56(20),2008,9592-9599.

[29]. D.B.Duncan, Multiple range and multiple "F" test. Biometrics, 11, 1955,1-42.

[30]. G.W.Snedecor, and W.G.Cochran,Statistical methods $\left(8^{\text {th }}\right.$ Ed., Iowa State University Press, Ames, Iowa, USA, 1990).

[31]. M.K.Goel, S.Mehrotra, and A.K.Kukreja, Elicitor-induced cellular and molecular events are responsible for productivity enhancement in hairy root cultures: an insight study. Appl Biochem Biotechnol,165(5-6),2011,1342-1355.

[32]. M.Bayraktar, E.Naziri, I.H.Akgun, F.Karabey, E.Ilhan, B.Akyol, E.Bedir, and A.Gure, Elicitor induced stevioside production, in vitro shoot growth, and biomass accumulation in micropropagated Stevia rebaudiana. Plant Cell Tiss Organ Cult 127,2016,289300 .

[33]. J.Palee, S.Dheeranupattana, S.Wangkarn, S.G.Pyne,and A.T.Ung,Effects of chitosan and salicylic acid on stemona alkaloid production in hydroponic culture of Stemona curtisii Hook. f. Chiang Mai J Sci, 43(5),2006,1070-1076.

[34]. N.Tocci, F.Ferrari, A.R.Santamaria, A.Valletta, I.Rovardi, and G.Pasqua, Chitosan enhances xanthone production in Hypericum perforatum subsp. angustifolium cell cultures. Nat Prod Res, 24(3),2010,286-293.

[35]. K.Muffler, D.Leipold, M.C.Scheller, C.Haas, J.Steingroewer, and T.Bley et al., Biotransformation of triterpenes. Process Biochem, 46,2011,1-15.

[36]. C.Deschamps, and J.E.Simon, Terpenoid essential oil metabolism in basil (Ocimum basilicum L.) following elicitation. $J$ Essent Oil Res, 18,2006,618-621.

[37]. G.Sivanandhan, M.Arun, S.Mayavan, M.Rajesh, T.S.Mariashibu, and M.Manickavasagam et al.,Chitosan enhances withanolides production in adventitious root cultures of Withania somnifera (L.) Dunal. Ind Crops Prod, 37(1),2012,124-129.

[38]. A.G.Namdeo, S.Patil, andD.P.Fulzele, Influence of fungal elicitors on production of ajmalicine by cell cultures of Catharanthus roseus. Biotechnol Prog,18(1),2002,159-162.

[39]. A.Yari Khosroushahi, M.Valizadeh, A.Ghasempour, M.Khosrowshahli, H.Naghdibadi, and M.Dadpour et al.,Improved taxol production by combination of inducing factors in suspension cell culture of Taxus baccata. Cell Biol Intl, 30(3),2006,262-269.

[40]. H.Gaosheng, and J.Jingming, Production of useful secondary metabolites through regulation of biosynthetic pathway in cell and tissue suspension culture of medicinal plants, in Recent advances in plantin vitroculture (http://www.intechopen.com/books/recentadvances-in-plant-invitro-culture, Intech, 2012).

[41]. V.S.Karwasara, R.Jain, P.Tomar, V.K.Dixit, Genetic transformation and elicitation as yield enhancement strategy for glycyrrhizin production by cell cultures of Abrus precatorius L. in vitro. Cell Dev Biol Plant,46,2010,354-362.

[42]. G.Trejo-Tapia,M.Carlos,C.-G.Rojas, M.Rodríguez-Monroy, A.C.Ramos-Valdivia, Monoterpenoid oxindole alkaloid production by Uncaria tomentosa (Willd) D.C. cell suspension cultures in a stirred tank bioreactor. Biotech Progress,21(3),2005,786-792.

[43]. S.Y.Chen, and S.Y.Huang, Shear stress effects on cell growth and 1-DOPA production by suspension culture of Stizolobium hasjoo cells in an agitated bioreactor. Bioprocess Eng, 22, 2000,5-12. 